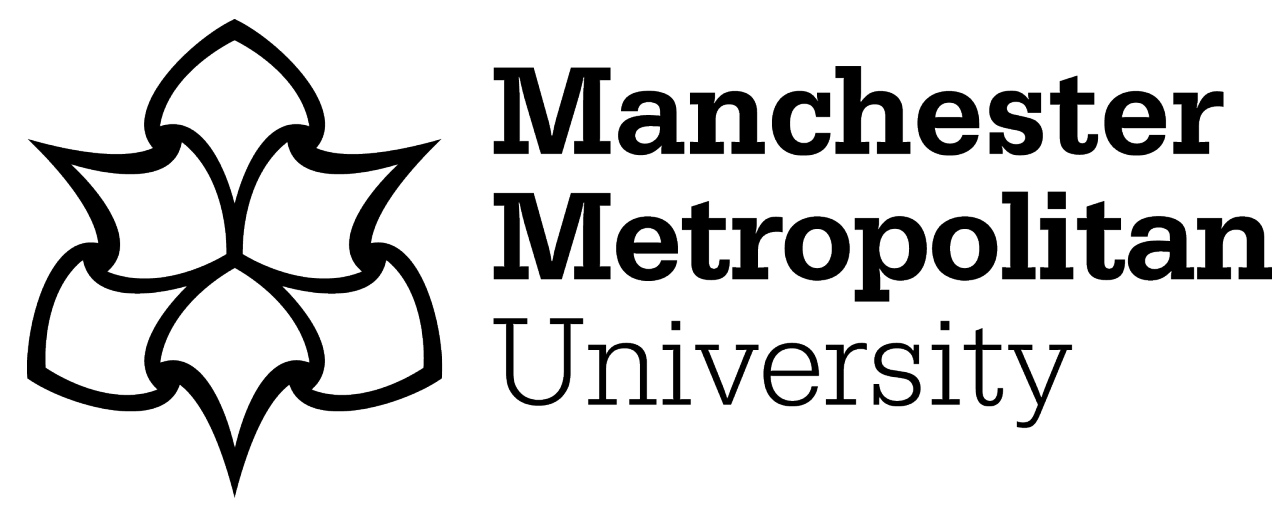

Shi, X, Beake, BD, Liskiewicz, TW ORCID logoORCID: https://orcid.org/0000-0002-0866-814X, Chen, J and Sun, Z (2019) Failure mechanism and protective role of ultrathin ta-C films on $\mathrm{Si}(100)$ during cyclic nano-impact. Surface and Coatings Technology, 364. pp. 32-42. ISSN 0257-8972

Downloaded from: https://e-space.mmu.ac.uk/623038/

Version: Accepted Version

Publisher: Elsevier

DOI: https://doi.org/10.1016/j.surfcoat.2019.02.082

Usage rights: Creative Commons: Attribution-Noncommercial-No Derivative Works 4.0

Please cite the published version 


\title{
Failure mechanism and protective role of ultrathin ta-C films on Si (100) during cyclic nano-impact
}

Xiangru Shi ${ }^{\mathrm{a}, \mathrm{b}}$, Ben D. Beake ${ }^{\mathrm{c}, *}$, Tomasz W. Liskiewicz ${ }^{\mathrm{b}}$, Jian Chen ${ }^{\mathrm{a}, *}$, Zhengming Sun $^{\mathrm{a}}$,

a. School of Materials Science and Engineering, Jiangsu Key Laboratory for Advanced Metallic Materials, Southeast University, Nanjing 211189, China

b. Institute of Functional Surface, School of Mechanical Engineering, University of Leeds, Leeds, LS2 9JT, United Kingdom

c. Micro Materials Ltd., Willow House, Yale Business Village, Ellice Way, Wrexham, LL13 7YL, United Kingdom

* Corresponding author. Tel: +86 25 52090688. E-mail address: j.chen@seu.edu.cn (Jian Chen), ben@micromaterials.co.uk (Ben Beake)

\begin{abstract}
Complex mechanical behaviour with phase transformation and high brittleness limits the reliability of silicon-based microelectromechanical systems. Although very hard ultra-thin films are being considered as protective overcoats to improve the service life of substrate materials, their resistance to fatigue can be at least as important as hardness when exposed to cyclic loading. In this study repetitive nano-impact tests with a spherical diamond probe have been used to investigate the fatigue behaviour and protective ability of 5 and $80 \mathrm{~nm}$ tetrahedral amorphous carbon (ta-C) films on silicon. At the lowest load there was delamination of the $80 \mathrm{~nm}$ film but not for the $5 \mathrm{~nm}$ film. At higher loads failure involved lateral cracking of the silicon substrate. Single impact tests showed that this was preceded by ring and radial cracking. Changing contact pressure during the test provided further support for the degradation mechanism and the influence of phase transformation in the Silicon substrate. Under repetitive contact
\end{abstract}


the thin film systems showed lower impact depth and greater impact cycles before substrate fracture than the uncoated Silicon. This is related to their enhanced load support which affects phase transformation in the substrate, with potentially delamination providing an additional impact energy dissipation mechanism.

Keywords: nano-impact; tetrahedral amorphous carbon; ultrathin films; silicon; failure mechanism

\section{Introduction}

Combining beneficial properties of high hardness, low friction, high wear resistance, and excellent chemical inertness, diamond-like carbon (DLC) films have been used in a wide range of industries [1-5]. For example, as protective coatings in silicon-based microelectromechanical system (MEMS) technology in which the relatively high brittleness and low fracture toughness at room temperature restrict their reliability under mechanical stress [6-8]. Another important application of DLC films is to act as overcoats for heads and magnetic media in hard disk and tape drive systems where the protective layers should be resistant to wear and corrosion, but thin enough not to impede the high density recording capability [9-12]. In both cases, film thickness is usually in the range from $2-100 \mathrm{~nm}$. Research into the protective ability of such ultrathin DLC coatings has employed a range of nanomechanical techniques including nanoindentation, nano-scratch, nano-fretting and nano-wear tests [13-16]. Crombez et al. [14] reported that the glass substrate coated with $2.2 \mathrm{~nm}$ DLC film showed significant improvement in resistance to cracking, delamination, and chipping in the scratch test. Using a diamond tip and $\mathrm{SiO}_{2}$ microsphere tip mounted on AFM, Chen et al. [15] reported that $2 \mathrm{~nm}$ and $5 \mathrm{~nm}$ DLC coatings on silicon substrate showed an increased critical load for indentation damage, scratch and wear resistance than the uncoated $\mathrm{Si}$, with the thicker coating showing more durability in protecting the silicon substrate.

In practical applications the film/substrate system will typically experience more 
complex loading conditions, where the hard coatings are more easily damaged by frequent and high speed impact load [13]. A tailored measurement method is needed to evaluate the fatigue properties and failure mechanism of ultra-thin coatings under repetitive impact loads. Over the past decade nano-impact testing has been used to study the localized impact fatigue behavior of a wide range of coatings such as nitinol-based shape memory alloy thin films [17.18], polymers [19], amorphous carbon films [20-23] and numerous other hard coatings [24-28]. In this test technique, repetitive high strain rate indentation occurs at the same location, and the evolution of film damage can be monitored in-situ, with a sharp increase in probe depth during the test typically occurring on brittle fracture. Faisal et al. [22.23] explored the influence of test methodology, indenter shape and impact loads on the failure mechanisms of $100 \mathrm{~nm}$ DLC films by nano-impact and multiple-load cycle indentations, in which two types of film failure were proposed based on the depth change at failure. The fracture properties of 5-80 nm tetrahedral amorphous carbon (ta-C) films deposited on silicon were investigated by repetitive nano-impact testing with a blunt Berkovich at impact load of 100-300 $\mu \mathrm{N}$ [21]. Under these conditions resistance to impact-induced fracture decreased as the film thickness increased. The impact loads applied in these studies were sufficiently low that the failure observed by the abrupt change in penetration depth was mainly caused by the cohesive failure of the films and/or the adhesive failure at the interface, without significant contribution from deformation or fracture of the substrate, which can play a critical role on the contact damage of thin films systems. Bernoulli et al. reported that to predict contact damage of DLC films of varying film thickness on titanium it was necessary to take account of the elastic-plastic behavior of the ductile substrate [29]. Borrero-López et al. studied the effect of different substrates on the contact damage of $1 \mu \mathrm{m}$ DLC films by simulating quasi-static and sliding contact [30]. It was proposed that a compliant and soft substrate promotes the initiation of ring/cone cracks on the film surface and propagate downwards towards the interface, while lateral cracks initiate in the stiff and hard substrate and then propagate upwards into the film. The presence of hard 5-80 nm tetrahedral amorphous carbon (ta-C) films can delay the phase transformation behavior of the silicon substrate by providing load support under 
nanoindentation, nano-scratch and nano-fretting tests [31-34].

In this current study the behaviour of 5 and $80 \mathrm{~nm}$ ta-C films on Si under repetitive impact with a spheroconical diamond probe has been compared to uncoated $\mathrm{Si}(100)$ substrate under the same conditions. The main aims were (i) to determine whether the thicker film would perform better, as it did in nano-scratch tests but not in previous nano-impact tests at very low load with Berkovich indenter (ii) if there is a switch in relative ranking in the impact tests under different conditions then why does this occur? (iii) to use a recently developed method for estimating the contact pressure evolution in impact test to determine the impact fatigue mechanism (iv) to determine the role of phase transformation of the Si substrate on the deformation process. The results will help to improve our understanding of the mechanical response, damage tolerance and failure mechanisms of Si-based MEMS devices operating under complex contact conditions, and deformation mechanisms of silicon on single particle impact, as occurs in abrasive jet micromachining [35].

\section{Experimental}

\subsection{Preparation and characterization of ta-C films}

The ta-C films with thickness of 5 and $80 \mathrm{~nm}$ (hereafter referred to as taC-5 and taC-80 respectively) were deposited on the single crystal silicon (100) substrate by filtered cathodic vacuum arc method (FCVA, Nanofilm Technologies Pte. Ltd) as described previously [21.31]. Prior to deposition, the silicon substrates were ultrasonically cleaned with deionized water for $10 \mathrm{~min}$, and then sputtered by dc argon ion beam for 3 min to remove the native oxide from the surface. A pure graphite target $(99.999 \%$, $70 \mathrm{~mm}$ diameter) was mounted onto a water-cooled copper block as the cathode. The substrate holder was in floating bias and the chamber was under a base pressure of 1.33 x $10^{-4} \mathrm{~Pa}$.

The thickness of the taC- 80 was measured by a surface profiler, while the thickness of the ultra-thin taC-5 coating was estimated based on the deposition rate [21]. The surface 
morphologies and surface roughness of the films was determined by atomic force microscopy (AFM) (Bruker Co., German). Raman spectra in the range of 1100-2000 $\mathrm{cm}^{-1}$ were obtained to investigate the bonding of GLC films by a Raman spectrometer (inVia-reflex, Renishaw Co., UK) using an Ar+ laser of $532 \mathrm{~nm}$.

\subsection{Nano-indentation and repetitive nano-impact testing}

A NanoTest system (Micro Materials Ltd, Wrexham, UK) was used for nanoindentation and cyclic nano-impact measurements. Hardness $(H)$ and elastic modulus $(E)$ measurements were from nanoindentation tests with a Berkovich diamond indenter at applied loads of $0.1-10 \mathrm{mN}$, details of which have been reported previously[34]. The measured reduced moduli $\left(E_{\mathrm{r}}\right)$ were converted to Elastic moduli using a Poisson's ratio of 0.2. Nano-impact testing was conducted with the pendulum impulse module [25], which allows precise control over the impact load and distance with a high-speed datalogging capability in the 1-5HZ rang (Figure 1(a)). A spheroconical diamond indenter with end radius $\sim 4.6 \mu \mathrm{m}$ was accelerated from a distance of $12 \mu \mathrm{m}$ above the sample surface to generate the impact using a solenoid connected to a timed relay. Each impact cycle was completed in $4 \mathrm{~s}$ including $2 \mathrm{~s}$ load on and $2 \mathrm{~s}$ load off time intervals (Figure 1(b)). The total testing time was $300 \mathrm{~s}$ corresponding to 75 repetitive impacts applied at the same surface site. The applied impact load was varied between 5, 10, 15, 20, 30 and $40 \mathrm{mN}$. Evolution of impact damage was followed in-situ by recording the probe depth signal versus time throughout the test. Ten repeat impact tests were performed at different positions for each load, as illustrated in Figure 1(c). Impact tests with the same testing conditions were also performed on uncoated silicon sample. Single impact tests were also performed at 10 and $30 \mathrm{mN}$. The impact morphology was observed by high resolution scanning electron microscopy (SEM, Hitachi SU8230). 

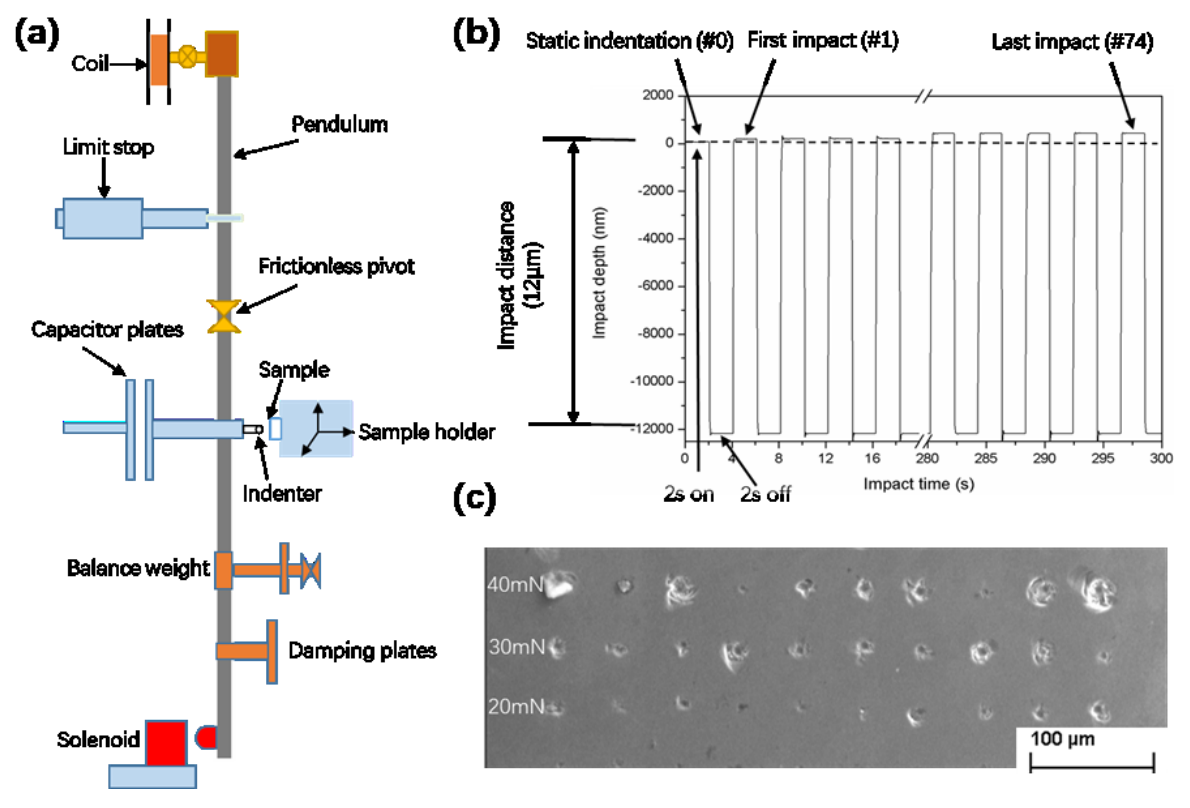

Figure 1. Nano-impact test configuration, (a) schematic illustration of the NanoTest system showing the pendulum configuration for impact test, (b) example test data (c) SEM image showing ten repeat impact tests under 20-40 $\mathrm{mN}$ impact load.

\section{Results}

\subsection{Microstructure and morphology of ta-C films}

Figure 2 shows the typical surface morphologies of ta-C films with different thickness. It can be seen that both of the surface is composed of large amount fine grains, and exhibit uniform and compact microstructure. The obtained surface roughness $\mathrm{R}_{\mathrm{a}}$ of two ta-C films is almost the same $0.15 \mathrm{~nm}$, which confirms the extremely smooth surface of the films.
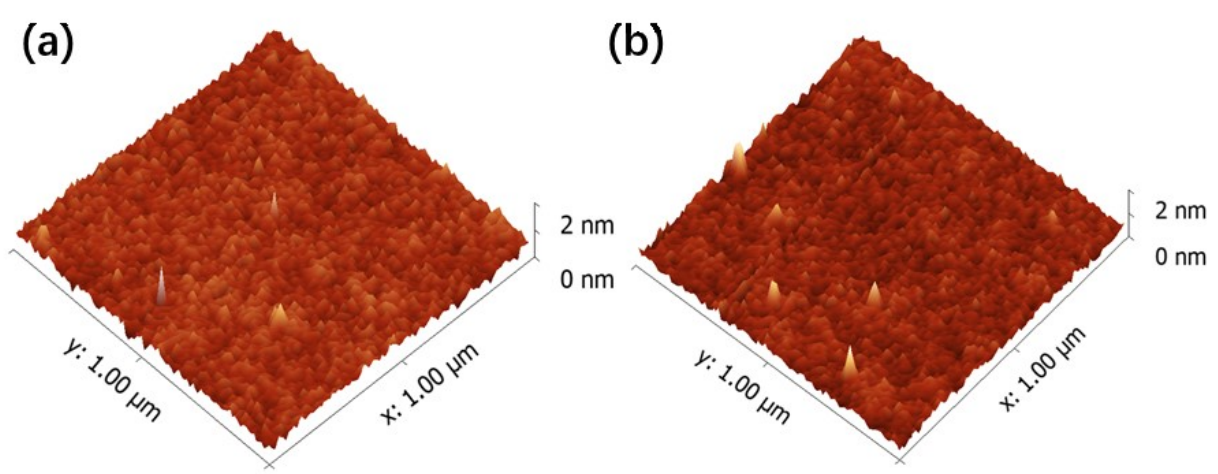

Figure 2. AFM images for surface morphology of (a) taC-5, (b) taC-80 samples. 
Raman spectroscopy was used to characterize the bond structure of the films, especially the relative content of $\mathrm{sp}^{3}$ carbon atoms. As shown in Figure 3, the spectra of taC-5 film is almost the same as that of taC-80 film, where a broad peak was appeared at approximately $1560 \mathrm{~cm}^{-1}$. Based on the Gaussian fitting, two typical characteristic peak can be obtained, one at approximately $1582 \mathrm{~cm}^{-1}$ (G peak) and another at approximately $1420 \mathrm{~cm}^{-1}$ (D peak). The relative $\mathrm{sp}^{3}$ content of the films can be estimated by the intensity ratio $I_{d} / I_{g}$ based on previous reports [36.37]. Hence, the $I_{d} / I_{g}$ ratio is measured for both of the films and found to be almost the same at around 0.26 , which corresponds to a $\mathrm{sp}^{3}$ content of about $75 \%$.

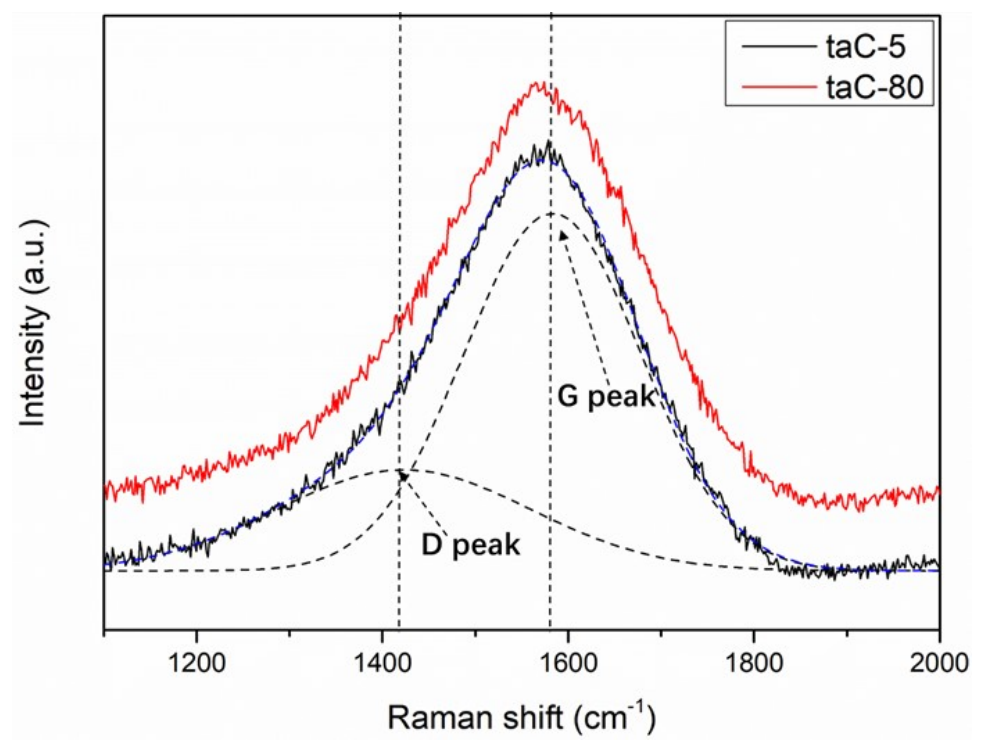

Figure 3. Raman spectra of ta-C films and the corresponding two fitted peaks.

\subsection{Nanoindentation}

The mechanical properties of both the films and the uncoated substrate are shown in Figure 4 as a function of the contact depth. As the contact depth increased the mechanical response of both coated systems became increasingly dominated by the mechanical properties of Si substrate. The taC-80 sample had higher hardness, $H / E$ and $H^{3} / E^{2}$ with the taC-5 sample exhibiting values similar to the silicon substrate. At $>60$ $\mathrm{nm}$ the elastic modulus of the coated systems was very close to the Si substrate. 

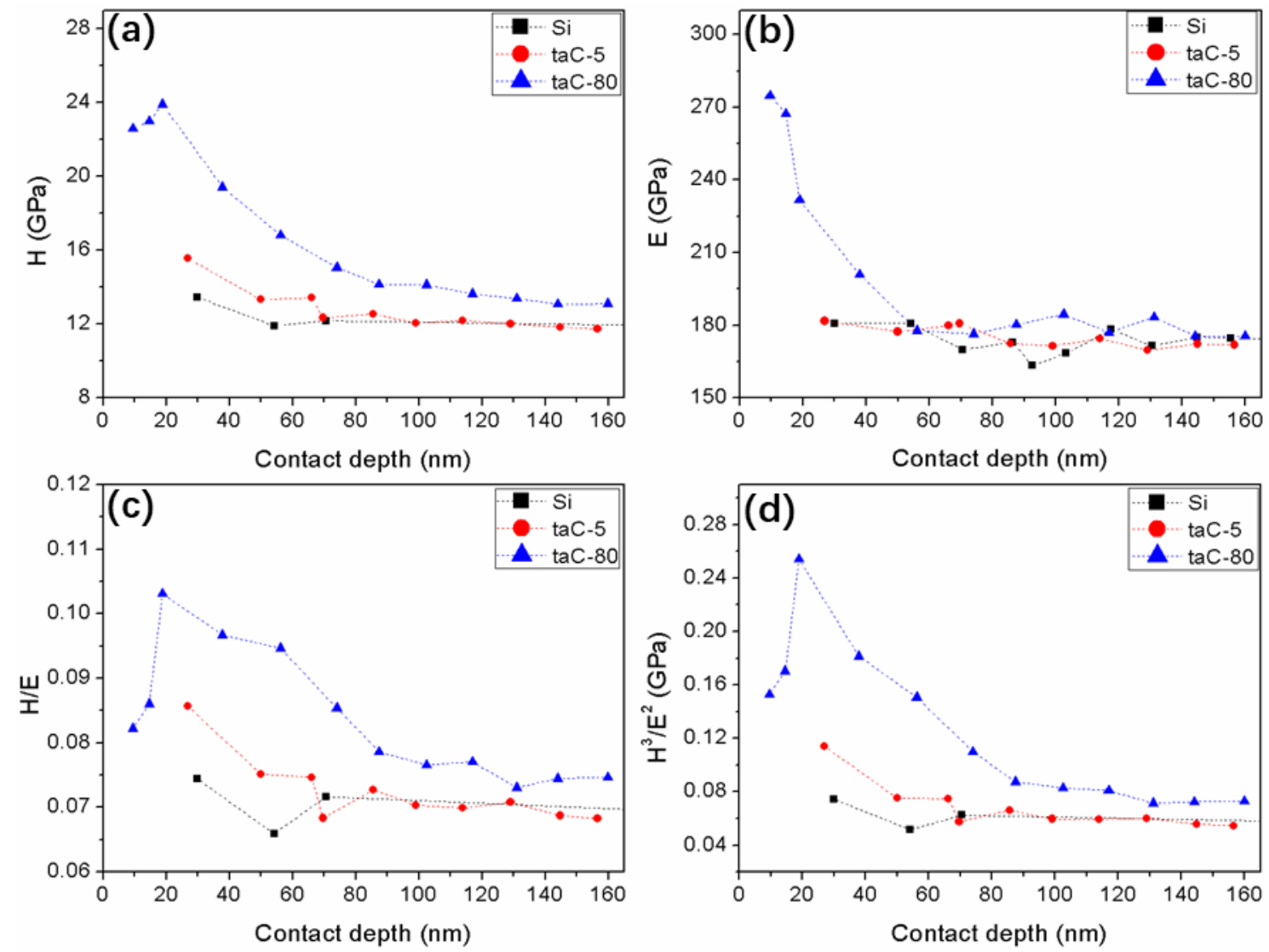

Figure 4. Variation in (a) hardness, (b) elastic modulus, (c) $H / E$, and (d) $H^{3} / E^{2}$ as a function of contact depth [data from refs. 20,31]

\subsection{Nano-impact testing}

In the nano-impact test the evolution of impact-induced damage (i.e. elastic and plastic deformation and fracture) with time is monitored cycle by cycle. To illustrate this, Figure 5(a) shows typical nano-impact depth vs. impact cycles results at the lowest impact load $(5 \mathrm{mN})$ for both ta-C films and the uncoated silicon substrate with the corresponding SEM images of the residual impact craters morphology (Fig. 5(b, c)). The increase in depth that occurs on the first impact is due to the dynamic force being greater than the static force. With further impacts on the Si substrate there was a gradual trend to increasing depth without any abrupt increases in depth during the 75 impact cycles. This type of behavior was observed in all the tests on Si under $5 \mathrm{mN}$ load. For the thin film samples, two types of response were observed: (i) slowly increasing impact depth (ii) a more rapid increase in penetration depth with fracture failure typically 
occurring around $35^{\text {th }}$ impact cycle. The more severe damage process occurred in $30 \%$ of the tests at $5 \mathrm{mN}$ on the taC-5 and $50 \%$ of tests on taC-80. In some of the tests on the taC-80 at $5 \mathrm{mN}$ the increase in depth during the test was close to the film thickness (e.g. from 30 to 75 impacts in Figure 5(a)) indicative of film removal. The corresponding SEM images show relatively minor substrate fracture at the edge of the impact crater for the $5 \mathrm{~nm}$ thick film (Figure 5(b)), while for the $80 \mathrm{~nm}$ film there is a large delamination area around the impact site but with no lateral cracking of the substrate (Figure 5(c)). In tests without fracture taC-80 showed the best impact resistance. To illustrate the stochastic behavior, the final depth at $5 \mathrm{mN}$ impact load is shown as a probability function in Figure 5(d). When the data are plotted in this way it can be seen that although the final depth for taC- 80 is lower than on the uncoated silicon, taC-5 has little protective effect at $5 \mathrm{mN}$.
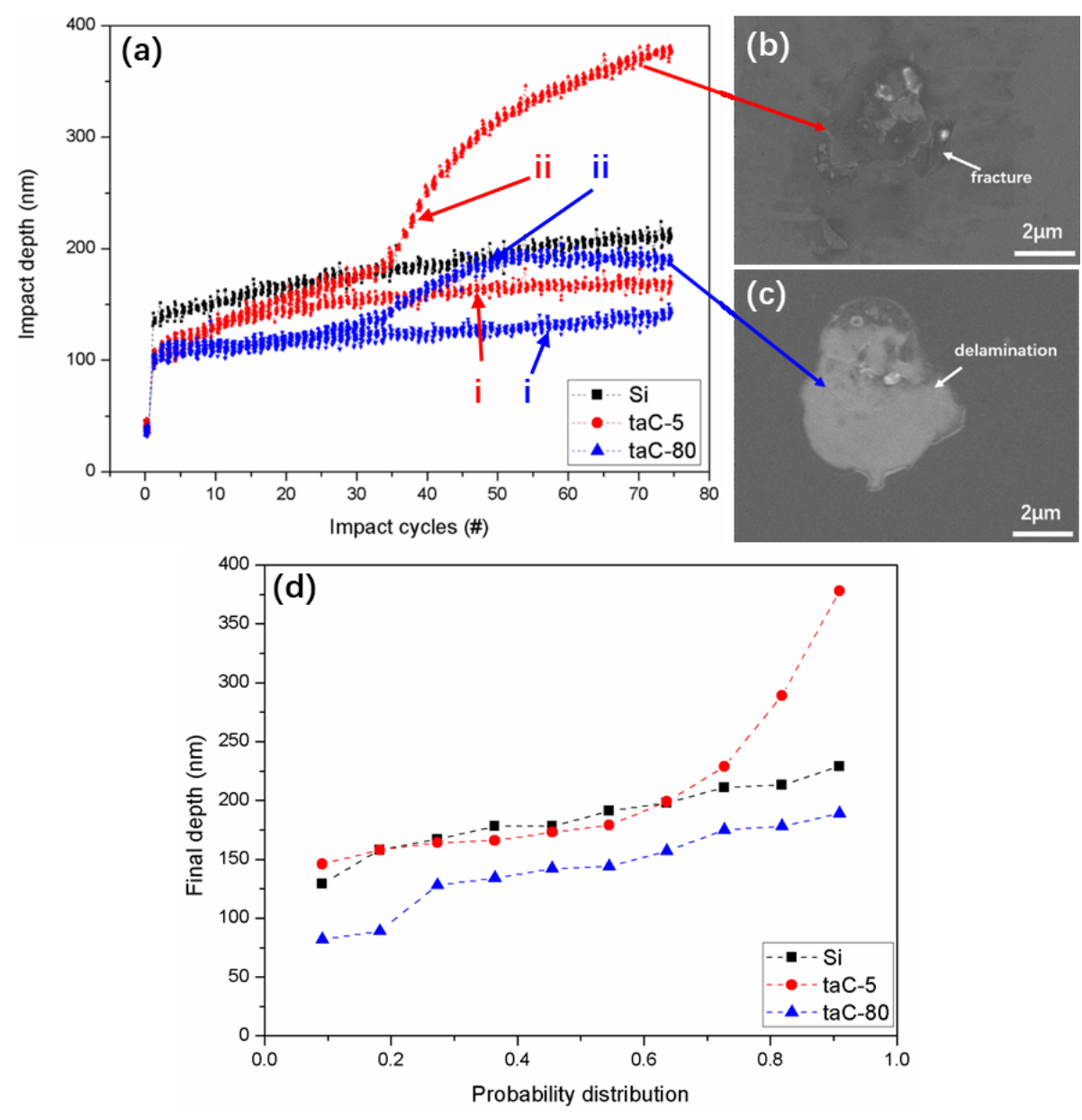

Figure 5. (a) Illustrative depth vs. impact cycles results at $5 \mathrm{mN}$ impact load (i) slowly 
increasing of impact depth, (ii) rapid increasing of impact depth for ta-C films; corresponding SEM images of impact craters on (b) taC-5, (c) taC-80, (d) probability distribution of the final impact depth at $5 \mathrm{mN}$ impact load.

Rapid increase of impact depth was observed in an increasing number of tests at impact loads of $10 \mathrm{mN}$ and above. Typical curves are shown in Figure 6. In tests at $10 \mathrm{mN}$ the increase in impact depth stabilized after a few cycles but then dramatically increased (Figure 6(a)). These fracture failures correlated with increasing load, with fewer cycles before the abrupt increase in impact depth at higher loads. The time-to-failure was longer for the ta-C films. 

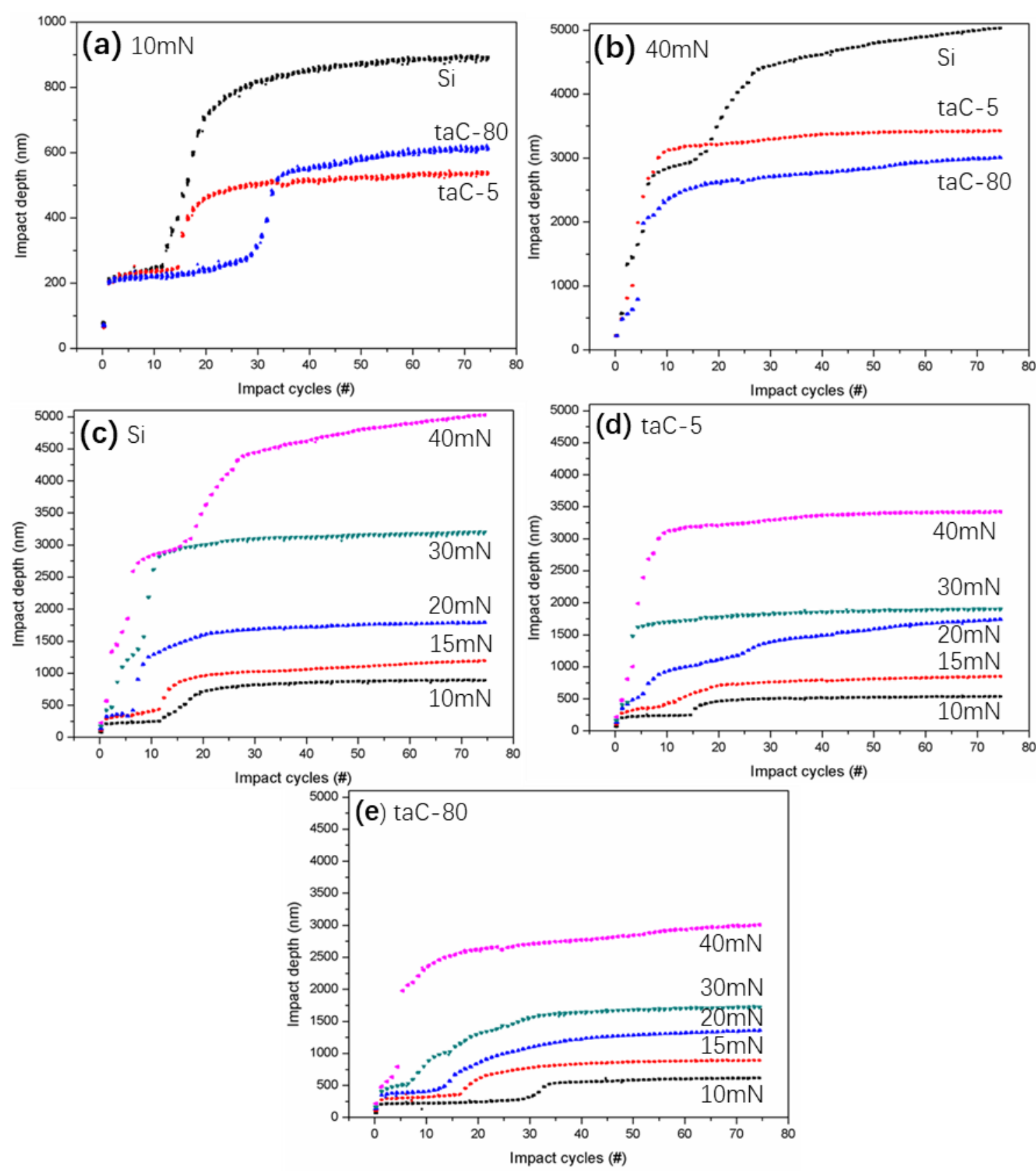

Figure 6. Typical nano-impact curves showing evolution of impact depth as a function of impact cycles at (a) $10 \mathrm{mN}$ and (b) $40 \mathrm{mN}$. Load dependence on (c) Si (d) taC-5, (e) taC-80.

The corresponding SEM images shown in Figure 7 reveal lateral cracking at the edges of the impact craters for both coated samples at impact loads above $10 \mathrm{mN}$, linked to characteristic brittle cracking behavior of Si substrate. Surface damage was more extensive at higher impact load, with pronounced cleavage fracture observed for both coated samples under $40 \mathrm{mN}$ impact load. The taC-80 film showed slightly better 
resistance to cracking with a smaller impact crater area. In addition to the lateral cracking of the substrate, apparent delamination can be observed at the edge of the impact crater for the taC-80 films, which was not observed for the taC-5.

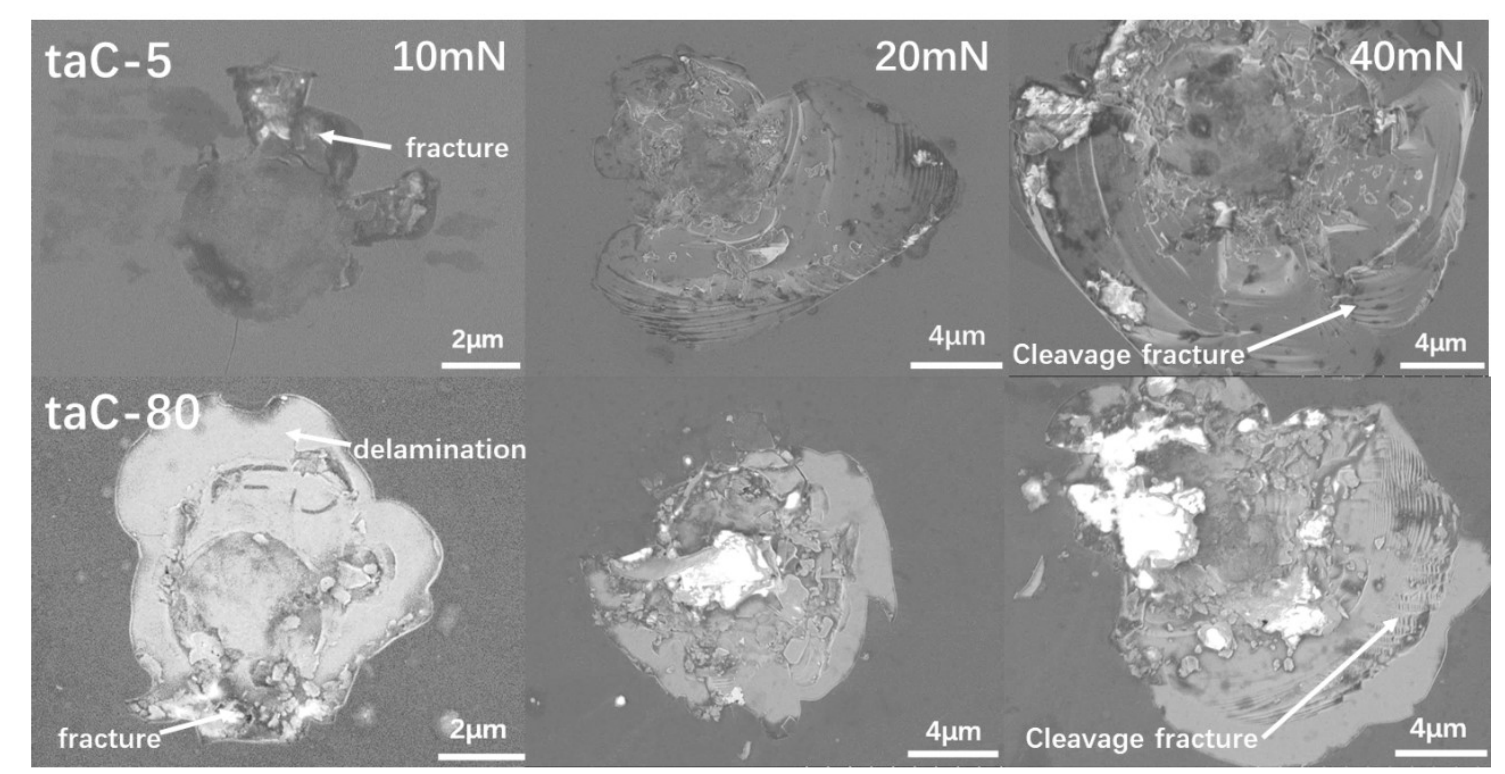

Figure 7. SEM images of representative nano-impact craters on 5 and $80 \mathrm{~nm}$ ta-C films under various impact loads.

In Figure 8 the mean depth from the 10 tests has been plotted as a function of impact load, for various number of impact cycles. In Figure 8(a) "static indentation" is the penetration depth recorded (under load) on the initial contact between the indenter and the surface under quasi-static load before the first impact. When the depth under load is predominantly the result of elastic and plastic deformation, the test shows good reproducibility and the standard deviation in the impact depth remains low. Once fracture occurred in some of the tests then the response became more stochastic (see also Figure 1(c)). The standard deviation of the impact depth can therefore be used to determine the onset of fracture. The error bars circled by the dashed ellipses in Figure 8 indicate that the fracture starts earlier at higher impact load. Both of the coated samples showed lower impact depth than the Si substrate during the early stages of the impact test before fracture, with the thicker one having a more marked benefit. 


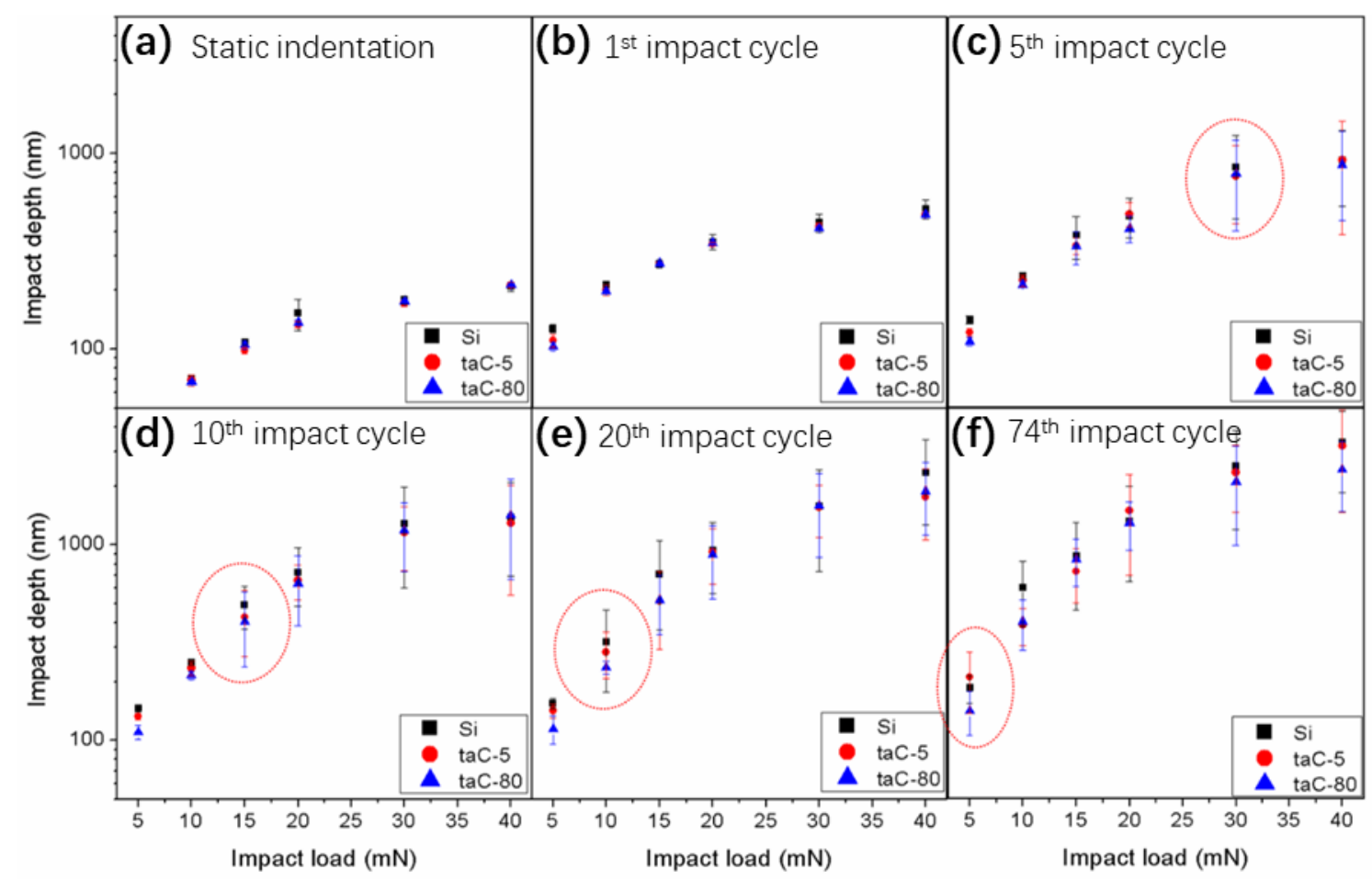

Figure 8. Evolution of the mean impact depth with increasing impact cycles as a function of impact load.

Figure 9 shows the probability of fracture estimated by ranking the impact cycles where a rapid depth increase occurred by assigning a probability of fracture failure $P(\mathrm{f})=$ $\mathrm{n} /(N+1)$ to the $\mathrm{n}^{\text {th }}$ ranked failure event in a total sample size of $N=10$ repeats under the same loading conditions [21]. Both films displayed some protective capability, as indicated by lower fracture probability and longer impact cycles to failure under 10-40 $\mathrm{mN}$ impact load, with the thicker film also showing more resistance to fracture at the end of the test. The probability of fracture varies with impact load. Figure 10 shows the $50 \%$ probability of failure in the form of $\mathrm{S}-\mathrm{N}$ curves. 


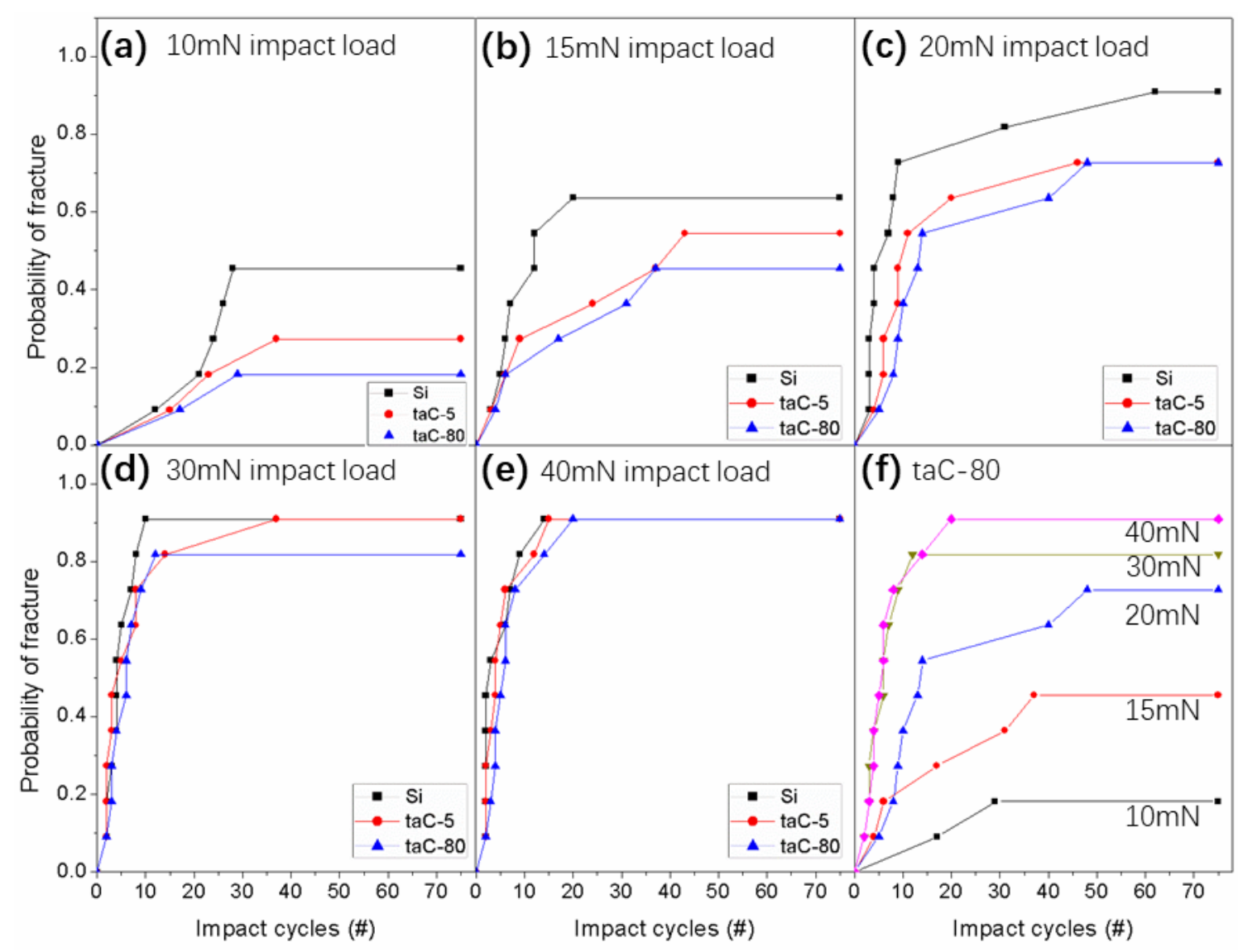

Figure 9. Variation in fracture probability with number of cycles under $10-40 \mathrm{mN}$ impact loads.

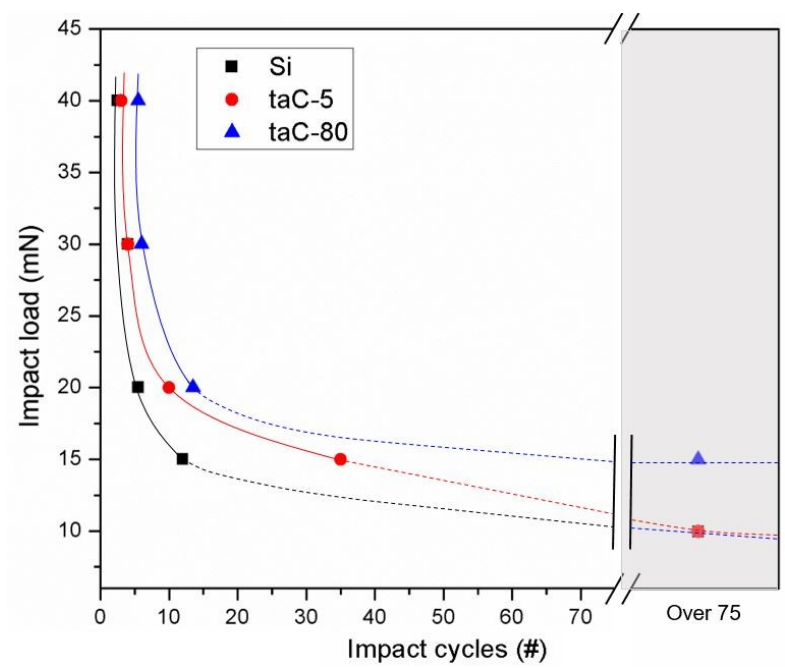

Figure $10.50 \%$ fracture probability under different impact loads as a function of impact cycles. 


\section{Discussion}

\subsection{The failure mechanism and protective role of ta-C films at low impact load}

Dynamic (or effective) forces during impact are higher than the static coil force. These can be estimated from a recently developed method [38] where the deformation is assumed to be rate-insensitive so that the same effective forces produce the same depths in impact and indentation tests when the same probe is used. In the following discussion the tests are referred to by the set impact load. The terminology "impact load" refers to the set static load in the test rather than the effective or dynamic force.

The deformation at $5 \mathrm{mN}$ is different to that found at higher loads. For the $80 \mathrm{~nm}$ ta-C film, the changing depth during that period is close to the thickness of the film, and the corresponding SEM (Figure 5 (c)) exhibited obvious film delamination without cracking on the substrate, which prove the fatigue failure and material removal of the $80 \mathrm{~nm}$ ta-C films at $5 \mathrm{mN}$ impact load. In a single quasi-static indentation test with the same probe at the same first impact depth $(110 \mathrm{~nm})$ as the effective force $(16 \mathrm{mN})$, the deformation was totally elastic. With repetitive contact under these conditions there is some non-elastic substrate deformation but it is very low and the damage proceeds by film fatigue. In nano-impact tests on these films with a blunt Berkovich indenter at very low impact forces $(100-300 \mu \mathrm{N})$ film-dominated behavior was also observed. There was gradual film failure after a period of fatigue, but subsequent substrate failure was not observed. The impact depth after the test was greater for the taC-80 than for taC-5, by an amount close to the difference in their thickness [21]. Low load (100-1000 $\mu \mathrm{N})$ nano-impact tests have also been performed on a $100 \mathrm{~nm}$ sputtered DLC on silicon with Berkovich and $10 \mu \mathrm{m}$ conical indenters by Faisal and co-workers [22.23.39]. They summarized the failure mechanisms at these very low loads as:- (i) some plastic deformation occurs in the film and substrate, and micro-cracks nucleate in the films after initial impact, (ii) the cracks continue to nucleate, coalesce and propagate to the film-substrate interface with little or no probe depth change during the first few impact cycles, (iii) debonding occurs at the interface with a more rapid depth increase due to 
the interfacial mismatch when the plastic deformation occurred and the relaxation of pre-existing residual stress in the film. In all of these studies the loads are sufficiently low that the stress fields were more concentrated in the film and permanent deformation of the Si was low.

In two tests at $5 \mathrm{mN}$ on the taC-5, there was a marked increase in probe depth, which SEM confirmed was due to the fracture of the silicon substrate (Figure 5(b)). Although it only occurred in a minority of tests, the substrate fracture could be an indication of a possible weakening effect of the thin film since it was not observed for the silicon substrate at the same impact load. Thin film weakening effects have been predicted by theoretical studies of quasi-static indentation contact [40-44]. In a FEA study of elastoplastic contact with a rigid surface Komvopoulos noted that very thin hard coatings may cause higher stresses in the substrate and correspondingly smaller critical load for the onset of plasticity compared to the uncoated substrate [40.41]. Sun et al. also used FEA to study elastic-plastic contact between a $100 \mu \mathrm{m}$ rigid sphere and TiN coatings with different thickness on high speed steel, titanium and aluminium [44]. The modelling results showed that when the coating thickness was below a critical limit the critical load for plasticity of the TiN/HSS system was lower than that for the uncoated substrate. Some experimental support for these ideas was provided by nanoindentation tests on 2 and $5 \mathrm{~nm}$ ultrathin DLC films on Si using a cube corner diamond indenter [15]. A threshold load, defined as the load above which the indentation damage will occur, was measured as 2-3 $\mathrm{mN}$ for the silicon substrate, $1-2 \mathrm{mN}$ for the $2 \mathrm{~nm}$ DLC films and 0.5$1 \mathrm{mN}$ for the $5 \mathrm{~nm}$ DLC films. If the taC-5 thin film is displaying potential weakening under repetitive contact at low load then it is a different type of behavior. For another possible reason, it may be attributed to the local stress concentrations in the impact area resulted from the aggregated carbon particles or defect formed during the deposition procedure by FVCA. Further investigation is required in future work to better understand this phenomenon.

\subsection{The failure mechanism and protective role of ta-C films at high impact load}


At $\geq 10 \mathrm{mN}$ impact load the films exhibited a similar type of impact response to the uncoated substrate, with the rapid increases in depth during the test far exceeding the film thickness. The impact tests show stochastic behavior which is more pronounced at higher load, as illustrated in Figure 1(c). As mentioned in the Results section this can provide an additional metric for the load vs. cycles relationship for onset of significant substrate fracture. SEM images confirmed lateral cracking and material removal in the silicon substrate accompanying film failure. Lateral cracking in silicon has also been reported in quasi-static indentation testing with the same probe, and with one similar sharpness $(R=4.3 \mu \mathrm{m}[45])$. However, the load required for this cracking (termed "giant pop-in" [45]) was at least $\sim 350 \mathrm{mN}$ with the $4.3 \mu \mathrm{m}$ probe and when loading to $500 \mathrm{mN}$ with the $4.6 \mu \mathrm{m}$ probe used in this work the failure did occurred in less than $50 \%$ of tests. The repetitive nano-impact technique induces these lateral cracks at much lower load than in quasi-static indentation. Lateral cracking occurred on both of the coated systems. However, lower mean impact depth and the larger number of impact cycles required before the rapid depth change shown in Figure 8 and 9 indicate that the thin film systems display some damage tolerance by delaying substrate failure and slightly reducing its severity.

It has been suggested that impact fatigue of a thin film system on repetitive contact with a spherical indenter proceeds by the following steps:- (i) over the first few impacts there is an increase in probe depth as the contact pressure decreases to the point at which the substrate no longer yields plastically. The increase in depth during this period is mainly attributed to the plastic deformation of the substrate. (ii) when the mean pressure is as low as the substrate yield stress the impact depth is approximately constant and grows gradually through coating fatigue (iii) after a fatigue period there is a transition to a more rapid rate of damage and (iv) ultimately failure of the coated system. The deformation mechanism is more complex when the substrate is silicon. At room temperature there is little dislocation-based plasticity in single crystal $\mathrm{Si}$ and its deformation is dominated by phase transformation (leading to 'pop-in' and 'pop-out' features in nanoindentation curves), accompanied by brittle fracture processes above a 
threshold load [46-49].
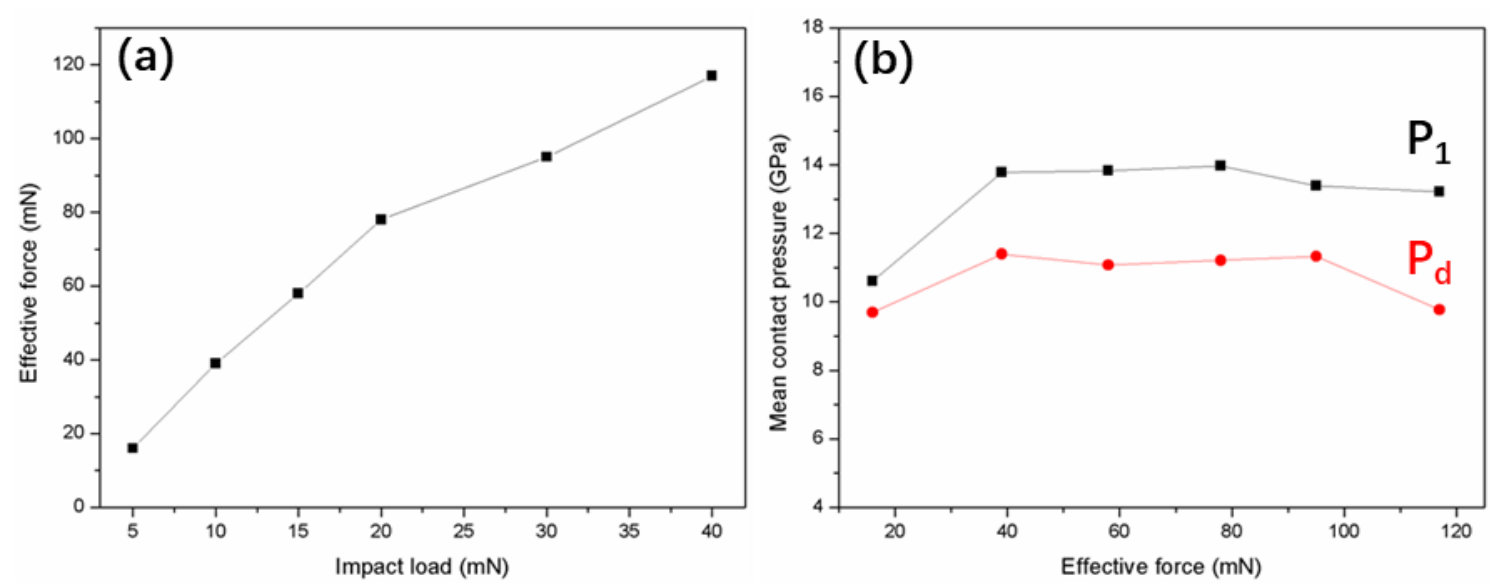

Figure 11. (a) The calculated effective force corresponding to the static impact load, (b) calculated mean contact pressure after first impact cycle $\left(P_{1}\right)$ and the mean contact pressure at the plateau depth $\left(P_{\mathrm{d}}\right)$.

The effective forces corresponding to the set static impact loads were estimated from equating depths in nanoindentation and after the initial impact, as shown in Figure 11 (a). The mean contact pressure after first impact cycle $\left(P_{1}\right)$, and after the impact depth increased to the plateau depth $\left(P_{\mathrm{d}}\right)$, were estimated from Hertzian analysis, as illustrated for taC-80 in Figure 11 (b). At $10 \mathrm{mN}$ impact load, the corresponding effective force is $39 \mathrm{mN}$. This is comparable with the load $(43 \mathrm{mN})$ at which the first pop-in occurred during single quasi-static loading with the same $4.6 \mu \mathrm{m}$ spherical indenter [34]. Pop-in in silicon occurs due to phase transformation from the diamond cubic ( $\mathrm{Si}-\mathrm{I})$ phase to the metallic $\beta-\mathrm{Sn}$ phase ( $\mathrm{Si}-\mathrm{II})$, involving a $22 \%$ increase in density at a pressure of 11.3-12.5 GPa [50.51]. With a $4.6 \mu \mathrm{m}$ spherical probe the deformation is almost completely elastic at a static load of $\sim 40 \mathrm{mN}$. The mean contact pressure of $13.8 \mathrm{GPa}$ in the initial impact estimated from the Hertzian analysis is above that required for phase transformation. Some phase transformation may also occur below the first detectable pop-in, as was observed by Bradby et al. in dark-field XTEM images prior to 'pop-in' in the elastic regime when using $4.2 \mu \mathrm{m}$ spherical indenter under a load of $20 \mathrm{mN}$ [48]. 


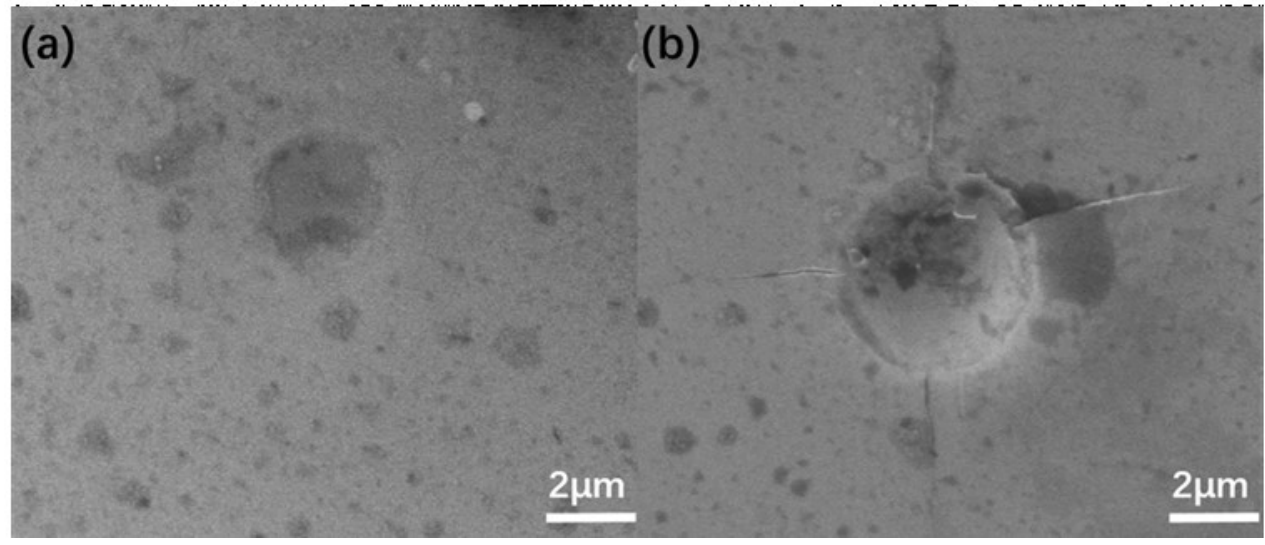

Figure 12. SEM images of the residual impression on taC-80 after a single impact under (a) $10 \mathrm{mN}$, (b) $40 \mathrm{mN}$ impact load.

Increasing the quasi-static impact load to $20 \mathrm{mN}$ produces an effective force comparable to that required for cracking in quasi-static loading, with more extensive cracking observed at higher load [46.52]. SEM images after a single impact on taC-80 at impact loads of (a) $10 \mathrm{mN}$ and (b) $40 \mathrm{mN}$ are shown in Figure 12. There is evidence of plastic deformation at the lower load, and radial cracks at the higher load.

Silicon undergoes rate-dependent phase changes during unloading. For slow unloading, the metallic phase (Si-II) transforms to a mixture of high pressure polycrystalline phases (Si-III and Si-XII), but on fast unloading predominantly transforms to amorphous silicon (a-Si) [53-57]. Similar rate dependence has been reported with Berkovich and $13.5 \mu \mathrm{m}$ spherical indenters [56.57]. Ruffell et al. [55] reported rapid unloading $(\sim 1000 \mathrm{mN} / \mathrm{s})$ results in the formation of $\alpha$-Si only, since almost no high pressure phases were observed by XTEM or Raman. If a material undergoes classical elastoplastic deformation, loading-unloading in subsequent indentation cycles would follow the unloading path of the first cycle and show an elastic response when $P_{\max }$ is a constant [58]. Further deformation occurs in the impact test since the depth increases in first few cycles. Although fracture has a more important role in the impact tests, particularly at higher load, multi-cycle quasi-static indentation experiments with spherical and Berkovich indenters [58-61] can shed some light on the deformation process. The indentation depth also increases during the first few load-unload cycles in 
these experiments and it has been determined that the amorphous phase transforms to high pressure phases during cyclic loading. This has been summarized as:- (i) Si-I transforms to Si-II during the first indentation cycle which transforms to a mixture of high pressure phases (Si-III/Si-XII) and a-Si during unloading, (ii) upon continued cycling the volume of a-Si gradually decreases and the proportion of Si-III/Si-XII increases to the point that a pop-out occurs transforming most of the remaining a-Si to Si-III/Si-XII, (iii) following pop-out, when the high pressure phases dominate the residual indent volume, the loading-unloading cycles quickly become elastic as any remaining a-Si is transformed to $\mathrm{Si}-\mathrm{III} / \mathrm{Si}-\mathrm{XII}[60]$.

In the nano-impact testing, the unloading is almost instantaneous, so the end phase after the first impact cycles should be predominantly a-Si. The first few impact cycles also result in continued plastic behavior of the silicon by phase transformation, where the volume of silicon substrate decrease slowly due to the conversion of a-Si to $\mathrm{Si}-\mathrm{III} / \mathrm{Si}$ XII, resulting in the gradual increase of impact depth. When the a-Si phases are totally transformed, the impact depth is close to constant value. The mean pressure (as illustrated for taC-80 in Figure 11(b)) decreases to 11.1-11.4 GPa, close to the yield stress of the Silicon substrate. In the impact test the elasto-plastic deformation is accompanied by cracking. Cracking will relieve stresses and slightly reduce the actual contact pressure [56]. With continued loading-unloading, the cyclic stresses result in crack growth, propagation and coalescence, and finally the happening of lateral cracking reflected by the rapid increase of impact depth. For impact load $>30 \mathrm{mN}$, the radial cracks can initiate at the first impact cycle and develop into lateral cracks rapidly, corresponding to the abrupt material removal in impact depth. This is the same degradation mechanism that is responsible for material removal on single particle impact in abrasive jet micromachining [35].

The critical loads for pop-outs during unloading with the $4.6 \mu \mathrm{m}$ spherical indenter were a function of the maximum load and unloading rate on Si and taC-80 [34]. Higher unloading rates favored elbow (gradual) pop-outs at lower critical load (and contact 
pressure) whilst slower unloading resulted in a greater proportion of sharp pop-outs at higher load. For a given set of conditions the critical load was lower on taC-80. The thin film modifies the contact pressure at which the unloading phase transformation occurs in an indentation, typically decreasing it by $\sim 2 \mathrm{GPa}$. The ability of the taC- 80 thin film to alter the mean contact pressures at which phase transformations occur during unloading influences the phase distribution and its evolution in the repetitive contacts by the spherical indenter in the nano-impact test which is expected to affect susceptibility to cracking. Compared to the thicker film, the lower $H$ and $H / E$ (Figure. 5) of $5 \mathrm{~nm}$ film-substrate system reduce the load capability of Si substrate to cause phase transformation and crack propagation, resulting in the worse protective role. Another important reason for the better protective role of thicker film than the thinner one may be attributed to the better adhesion strength between the film and substrate, reflected by the nano-scratch testing in our previous studies [31.34].

In summary, the taC-80, and to a much lesser effect taC-5, provides some protection against contact damage in silicon from impact loading by the $R=4.6 \mu \mathrm{m}$ spherical indenter. At low load the high hardness of the ta-C films restricts the occurrence and development of the phase transformation in the silicon substrate by providing load support, lowering the contact-induced stresses in the substrate. The taC-80 also has a higher resistance to plastic deformation $\left(H^{3} / E^{2}\right)$ which enables the deformation to be spread out over a wider area. In quasi-static nanoindentation with the same $R=4.6 \mu \mathrm{m}$ indenter [34] the load at which pop-in occurred was slightly higher $(43 \mathrm{mN})$ on taC-80, than on the silicon substrate $(37 \mathrm{mN})$. Fracture and delamination of the film will absorb part of the impact energy, which may also reduce the stresses reaching the substrate, retarding the initiation and propagation of the cracks in the substrate. At higher load fracture is unavoidable but the taC-80 is capable of modifying the mean contact pressures for phase transformation.

\section{Conclusions}

Repetitive nano-impact testing has been used to investigate the influence of 5 and 80 
$\mathrm{nm}$ ta-C thin films on modifying the damage tolerance of Si substrate with a spherical indenter. At low impact load the failure mechanisms involve film damage with minimal permanent substrate damage, with delamination on taC-80. At higher loads fracture of silicon substrate occurs, more rapidly and extensively as the load increases. The failure mechanism involves initial plastic deformation through phase transformation during the first few impact cycles, and subsequent brittle fracture after the completed plastic deformation. The ultrathin films play a protective role by retarding the development of phase transformation and propagation of cracks due to their high hardness and the energy absorption when fracture and delamination occurred in the films. The thicker film has a better protective role than the thinner one.

\section{Acknowledgments}

The authors gratefully acknowledge the financial support from the NSFC (\#11472080), the NSF of Jiangsu Province (\#BK20141336), the Fundamental Research Funds for the

Central Universities, the financial support from the program of China Scholarships Council (No. 201706090126), and the postgraduate training innovation project of Jiangsu Province (KYLX16_0198).

\section{References:}

[1]R. Hauert, A review of modified DLC coatings for biological applications, DIAM. RELAT. MATER., 12(2003) 583-589.

[2]S.D.A. Lawes, M.E. Fitzpatrick, S.V. Hainsworth, Evaluation of the tribological properties of DLC for engine applications, Journal of Physics D: Applied Physics, 40(2007) 5427-5437.

[3]B. Podgornik, J. Vižintin, Tribological reactions between oil additives and DLC coatings for automotive applications, Surface and Coatings Technology, 200(2005) 1982-1989.

[4]L. Léger, Deciphering the tangled web, MATER TODAY, 11(2008) 58.

[5]E. Peiner, A. Tibrewala, R. Bandorf, H. Luethje, L. Doering, W. Limmer, Diamond-like carbon for MEMS, J. MICROMECH. MICROENG., 17(2007) S83-S90.

[6]C. Muhlstein, S. Brown, Reliability and Fatigue Testing of MEMS, Springer Netherlands, 1998.

[7]H. Fujita, MEMS and tribology, JOURNAL OF JAPANESE SOCIETY OF TRIBOLOGISTS, 49(2004) 112-121.

[8]J.K. Luo, Y.Q. Fu, H.R. Le, J.A. Williams, S.M. Spearing, W.I. Milne, Diamond and diamond-like carbon MEMS, J. MICROMECH. MICROENG., 17(2007) S147-S163.

[9]Z.H. Liu, J.F. Zhao, J. McLaughlin, A study of microstructural and electrochemical properties of ultra-thin DLC coatings on AlTiC substrates deposited using the ion beam technique, DIAM. 
RELAT. MATER., 8(1999) 56-63.

[10]J. Robertson, Requirements of ultrathin carbon coatings for magnetic storage technology, TRIBOL. INT., 36(2003) 405-415.

[11]J.X. Liao, E.Q. Li, Z. Tian, X.F. Pan, J. Xu, L. Jin, H.G. Yang, Tribological performance of ultrathin diamond-like carbon films prepared by plasma-based ion implantation, Journal of Physics D: Applied Physics, 41(2008) 55305.

[12]H. Han, F. Ryan, M. Mcclure, Ultra-thin tetrahedral amorphous carbon film as slider overcoat for high areal density magnetic recording, SURF. COAT. TECH., s 120 - 121(1999) 579-584.

[13]X. Li, B. Bhushan, Evaluation of fracture toughness of ultra-thin amorphous carbon coatings deposited by different deposition techniques, THIN SOLID FILMS, 355-356(1999) 330-336.

[14]R. Crombez, J. McMinis, V.S. Veerasamy, W. Shen, Experimental study of mechanical properties and scratch resistance of ultra-thin diamond-like-carbon (DLC) coatings deposited on glass, TRIBOL. INT., 44(2011) 55-62.

[15]L. Chen, M.C. Yang, C.F. Song, B.J. Yu, L.M. Qian, Is $2 \mathrm{~nm}$ DLC coating enough to resist the nanowear of silicon, WEAR, 302(2013) 909-917.

[16]S. Miyake, Y. Takahashi, M. Wang, T. Saito, Durability evaluation of perfluoropolyether-lubricantcoated protective diamond-like carbon film by the lateral vibration friction test, Journal of Physics D: Applied Physics, 38(2005) 2244-2252.

[17]N.H. Faisal, R. Ahmed, R. Fu, Nano-Impact (Fatigue) Characterization of As-Deposited Amorphous Nitinol Thin Film, COATINGS, 2(2012) 195-209.

[18]N. Choudhary, D.K. Kharat, J. Van Humbeeck, D. Kaur, NiTi/Pb(Zr0.52Ti0.48)O3 thin film heterostructures for vibration damping in MEMS, Sensors and Actuators A: Physical, 193(2013) 30-34.

[19]B.D. Beake, G.A. Bell, S.R. Goodes, N.J. Pickford, J.F. Smith, Improved nanomechanical test techniques for surface engineered materials, SURF. ENG., 26(2010) 37-49.

[20]B.D. Beake, S.R. Goodes, J.F. Smith, R. Madani, C.A. Rego, R.I. Cherry, T. Wagner, Investigating the fracture resistance and adhesion of DLC films with micro-impact testing, Diamond \& Related Materials, 11(2002) 1606-1609.

[21]B.D. Beake, S.P. Lau, J.F. Smith, Evaluating the fracture properties and fatigue wear of tetrahedral amorphous carbon films on silicon by nano-impact testing, Surface and Coatings Technology, 177178(2004) 611-615.

[22]N.H. Faisal, R. Ahmed, S. Goel, Y.Q. Fu, Influence of test methodology and probe geometry on nanoscale fatigue failure of diamond-like carbon film, Surface and Coatings Technology, 242(2014) 42-53.

[23]N.H. Faisal, R. Ahmed, Y.Q. Fu, Y.O. Elakwah, M. Alhoshan, Influence of indenter shape on DLC film failure during multiple load cycle nanoindentation, Materials Science \& Technology, 28(2012) 1186-1197.

[24]J. Chen, H. Li, B.D. Beake, Load sensitivity in repetitive nano-impact testing of TiN and AlTiN coatings, Surface and Coatings Technology, 308(2016) 289-297.

[25]J.M. Wheeler, A.G. Gunner, Analysis of failure modes under nano-impact fatigue of coatings via high-speed sampling, Surface and Coatings Technology, 232(2013) 264-268.

[26]B.D. Beake, V.M. Vishnyakov, J.S. Colligon, Nano-impact testing of TiFeN and TiFeMoN films for dynamic toughness evaluation, Journal of Physics D: Applied Physics, 44(2011) 85301.

[27]J. Chen, B.D. Beake, R.G. Wellman, J.R. Nicholls, H. Dong, An investigation into the correlation 
between nano-impact resistance and erosion performance of EB-PVD thermal barrier coatings on thermal ageing, Surface and Coatings Technology, 206(2012) 4992-4998.

[28]J. Chen, R. Ji, R.H.U. Khan, X. Li, B.D. Beake, H. Dong, Effects of mechanical properties and layer structure on the cyclic dynamic loading of TiN-based coatings, Surface and Coatings Technology, 206(2011) 522-529.

[29]D. Bernoulli, A. Wyss, R. Raghavan, K. Thorwarth, R. Hauert, R. Spolenak, Contact damage of hard and brittle thin films on ductile metallic substrates: an analysis of diamond-like carbon on titanium substrates, J. MATER. SCI., 50(2015) 2779-2787.

[30]O. Borrero-López, M. Hoffman, A. Bendavid, P.J. Martin, Substrate effects on the mechanical properties and contact damage of diamond-like carbon thin films, DIAM. RELAT. MATER., 19(2010) 1273-1280.

[31]B.D. Beake, S.P. Lau, Nanotribological and nanomechanical properties of $5-80 \mathrm{~nm}$ tetrahedral amorphous carbon films on silicon, DIAM. RELAT. MATER., 14(2005) 1535-1542.

[32]B.D. Beake, T.W. Liskiewicz, N.J. Pickford, J.F. Smith, Accelerated nano-fretting testing of Si(100), TRIBOL. INT., 46(2012) 114-118.

[33]B.D. Beake, T.W. Liskiewicz, J.F. Smith, Deformation of $\operatorname{Si(100)}$ in spherical contacts Comparison of nano-fretting and nano-scratch tests with nano-indentation, Surface and Coatings Technology, 206(2011) 1921-1926.

[34]B.D. Beake, M.I. Davies, T.W. Liskiewicz, V.M. Vishnyakov, S.R. Goodes, Nano-scratch, nanoindentation and fretting tests of 5-80 nm ta-C films on $\mathrm{Si}(100)$, WEAR, 301(2013) 575-582.

[35]A.K. Basak, J.M. Fan, J. Wang, P. Mathew, Material removal mechanisms of monocrystalline silicon under the impact of high velocity micro-particles, WEAR, 269(2010) 269-277.

[36]D. Sheeja, B.K. Tay, S.P. Lau, X. Shi, X. Ding, Structural and tribological characterization of multilayer ta-C films prepared by filtered cathodic vacuum arc with substrate pulse biasing, SURF. COAT. TECH., 132(2000) 228-232.

[37]D. Sheeja, B.K. Tay, S.P. Lau, X. Shi, J. Shi, Y. Li, X. Ding, E. Liu, Z. Sun, Characterization of taC films prepared by a two-step filtered vacuum arc deposition technique, SURF. COAT. TECH., 127(2000) 246-250.

[38] B.D. Beake, T.W. Liskiewicz, A. Bird, X. Shi, Micro-scale Impact testing - a new approach to studying fatigue resistance in hard carbon coatings, submitted to Tribol. Int.

[39]R. Ahmed, Y.Q. Fu, N.H. Faisal, Fatigue at Nanoscale: An Integrated Stiffness and Depth Sensing Approach to Investigate the Mechanisms of Failure in Diamondlike Carbon Film, J. TRIBOL.-T. ASME, 134(2012).

[40]K. KOMVOPOULOS, FINITE-ELEMENT ANALYSIS OF A LAYERED ELASTIC SOLID IN NORMAL CONTACT WITH A RIGID SURFACE, J. TRIBOL.-T. ASME, 110(1988) 477-485.

[41]K. KOMVOPOULOS, ELASTIC-PLASTIC FINITE-ELEMENT ANALYSIS OF INDENTED LAYERED MEDIA, J. TRIBOL.-T. ASME, 111(1989) 430-439.

[42]H. DJABELLA, R.D. ARNELL, FINITE-ELEMENT ANALYSIS OF THE CONTACT STRESSES IN ELASTIC COATING SUBSTRATE UNDER NORMAL AND TANGENTIAL LOAD, THIN SOLID FILMS, 223(1993) 87-97.

[43]R. Goltsberg, I. Etsion, A model for the weakening effect of very thin hard coatings, WEAR, 308(2013) 10-16.

[44]Y. Sun, A. Bloyce, T. Bell, Finite element analysis of plastic deformation of various TiN coating/ substrate systems under normal contact with a rigid sphere, THIN SOLID FILMS, 271(1995) 122- 
131.

[45]D.J. Oliver, B.R. Lawn, R.F. Cook, M.G. Reitsma, J.E. Bradby, J.S. Williams, P. Munroe, Giant pop-ins in nanoindented silicon and germanium caused by lateral cracking, J. MATER. RES., 23(2008) 297-301.

[46]S. Jiapeng, L. Cheng, J. Han, A. Ma, L. Fang, Nanoindentation Induced Deformation and Pop-in Events in a Silicon Crystal: Molecular Dynamics Simulation and Experiment, SCI REP-UK, 7(2017).

[47]Domnich, V. Vladislav, Phase transformations in silicon induced by contact loading., (2002).

[48]J.E. Bradby, J.S. Williams, J. Wong-Leung, M.V. Swain, P. Munroe, Mechanical deformation in silicon by micro-indentation, J. MATER. RES., 16(2001) 1500-1507.

[49]J.J. Gilman, Why silicon is hard, SCIENCE, 261(1993) 1436-1439.

[50]J.E. Bradby, J.S. Williams, M.V. Swain, In situ electrical characterization of phase transformations in Si during indentation, PHYS. REV. B, 67(2003).

[51]R. Abram, D. Chrobak, R. Nowak, Origin of a Nanoindentation Pop-in Event in Silicon Crystal, PHYS. REV. LETT., 118(2017) 95502.

[52]A.M. Minor, E.T. Lilleodden, M. Jin, E.A. Stach, D.C. Chrzan, J.W. Morris, Room temperature dislocation plasticity in silicon, PHILOS. MAG., 85(2005) 323-330.

[53]L. Chang, L.C. Zhang, Deformation mechanisms at pop-out in monocrystalline silicon under nanoindentation, ACTA MATER., 57(2009) 2148-2153.

[54]S. Ruffell, J.E. Bradby, N. Fujisawa, J.S. Williams, Identification of nanoindentation-induced phase changes in silicon byin situ electrical characterization, J. APPL. PHYS., 101(2007) 83531.

[55]S. Ruffell, J.E. Bradby, J.S. Williams, P. Munroe, Formation and growth of nanoindentation-induced high pressure phases in crystalline and amorphous silicon, J. APPL. PHYS., 102(2007) 63521.

[56]T. Juliano, V. Domnich, Y. Gogotsi, Examining pressure-induced phase transformations in silicon by spherical indentation and Raman spectroscopy: A statistical study, J. MATER. RES., 19(2004) 3099-3108.

[57]T. Juliano, Y. Gogotsi, V. Domnich, Effect of indentation unloading conditions on phase transformation induced events in silicon, J. MATER. RES., 18(2003) 1192-1201.

[58]I. Zarudi, L.C. Zhang, M.V. Swain, Behavior of monocrystalline silicon under cyclic microindentations with a spherical indenter, APPL. PHYS. LETT., 82(2003) 1027-1029.

[59]N. Fujisawa, J.S. Williams, M.V. Swain, On the cyclic indentation behavior of crystalline silicon with a sharp tip, J. MATER. RES., 22(2007) 2992-2997.

[60]N. Fujisawa, S. Ruffell, J.E. Bradby, J.S. Williams, B. Haberl, O.L. Warren, Understanding pressureinduced phase-transformation behavior in silicon throughin situ electrical probing under cyclic loading conditions, J. APPL. PHYS., 105(2009) 106111.

[61]I. Zarudi, L.C. Zhang, M.V. Swain, Microstructure evolution in monocrystalline silicon in cyclic microindentations, J. MATER. RES., 18(2003) 758-761. 